\title{
Hydrogen-rich solution attenuates myocardial injury caused by cardiopulmonary bypass in rats via the Janus-activated kinase 2/signal transducer and activator of transcription 3 signaling pathway
}

\author{
KEYAN CHEN $^{1}$, YINGJIE SUN ${ }^{2}$, YUGANG DIAO $^{2}$, TIEZHENG ZHANG $^{2}$ and WANWEI DONG ${ }^{1}$ \\ ${ }^{1}$ Department of Laboratory Animal Science, China Medical University, Shenyang, Liaoning 110122; \\ ${ }^{2}$ Department of Anesthesiology, General Hospital of Shenyang Military Area Command, \\ Shenyang, Liaoning 110016, P.R. China
}

Received April 6, 2017; Accepted March 14, 2018

DOI: $10.3892 / \mathrm{ol} .2018 .8639$

\begin{abstract}
The incidence of complications and mortality following open-heart surgery with cardiopulmonary bypass $(\mathrm{CPB})$ is associated with the severity of the myocardial injury that occurs during surgery. Hydrogen-rich solution (HRS) may prevent antioxidant stress and inhibit apoptosis and inflammation. The present study was designed to investigate the effects of HRS on CPB-induced myocardial injury, and to investigate its potential regulation of the Janus-activated kinase 2/signal transducer and activator of transcription 3 (JAK2/STAT3) pathway. The HRS treatment resulted in the significant upregulation of malonyl dialdehyde (MDA) and myeloperoxidase (MPO), whilesuperoxide dismutase (SOD) levels were significantly downregulated, compared with the Sham group $(\mathrm{P}<0.05)$. Additionally, HRS treatment improved myocardial injury, and decreased the expression levels of cardiac troponins, heart-type fatty acid binding protein, interleukin (IL)-1 $\beta$, IL-6, tumor necrosis factor (TNF)- $\alpha$, MDA and MPO, and increased SOD release in CPB rats $(\mathrm{P}<0.05)$. Additionally, in the CPB group without the HRS treatment, the expression levels of B-cell lymphoma (Bcl)-2, JAK2, phospho-JAK2 (p-JAK2), STAT3 and phospho-STAT3 (p-STAT3) were significantly decreased, and Bax was significantly increased, compared with the Sham group $(\mathrm{P}<0.05)$. By contrast, compared with the CPB group, the expression levels of B-cell lymphoma 2 (Bcl-2), JAK2, phosphorylated (p)-JAK2, STAT3 and p-STAT3 in the HRS group were significantly increased, and $\mathrm{Bcl}-2$-associated $\mathrm{X}$ protein expression was significantly
\end{abstract}

Correspondence to: Dr Wanwei Dong, Department of Laboratory Animal Science, China Medical University, 77 Puhe Road, Shenyang, Liaoning 110122, P.R. China

E-mail: wwdong@cmu.edu.cn

Key words: hydrogen-rich solution, cardiopulmonary bypass, Janus-activated kinase 2, apoptosis, inflammation decreased $(\mathrm{P}<0.05)$. In JAK2 knockdown experiments using siRNA, HRS treatment following hypoxia/reoxygenation also significantly increased the viability of myocardial cells, decreased the rate of myocardial cell apoptosis, elevated the levels of SOD and suppressed the release of MDA and lactate dehydrogenase in the control siRNA and CPB groups $(\mathrm{P}<0.05)$. Furthermore, JAK2 siRNA attenuated these protective effects of HRS ( $\mathrm{P}<0.05$ vs. control siRNA, HRS and CPB groups). Additionally, the results demonstrated that the HRS treatment significantly increased the expression levels of p-JAK2, p-STAT3 and Bcl-2 in myocardial cells following hypoxia and decreased Bax expression in the control siRNA and CPB groups $(\mathrm{P}<0.05)$. In addition, JAK2 siRNA was determined to attenuate these effects of HRS $(\mathrm{P}<0.05$ vs. control siRNA, HRS and CPB groups). Taken together, these results indicated that HRS may alleviate CPB-induced myocardial injury, inhibit myocardial cell apoptosis and protect myocardial cells through regulation of the JAK2/STAT3 signaling pathway.

\section{Introduction}

Cardiopulmonary bypass (CPB) refers to a series of procedures that involve the connection of blood vessels to a heart-lung machine in order to produce in vitro oxygenation of venous blood, and subsequently the transfer of oxygenated blood into the arterial system (1). With improvements in CPB and surgical techniques, an increasing number of congenital and acquired cardiovascular diseases may be treated using surgery (2). During CPB, complications, including aortic blockage and cardiac arrest, as well as resuscitation, may trigger myocardial ischemia and hypoxia-reperfusion injury, which may impair cardiac function and lead to postoperative malignant arrhythmias and low cardiac output syndrome $(3,4)$. The incidence of complications and mortality following open-heart surgery with $\mathrm{CPB}$ is associated with the severity of myocardial injury that occurs during surgery, and $\geq 25 \%$ of postoperative mortalities are associated with malignant cardiovascular complications of surgery $(5,6)$. Additionally, previous studies have demonstrated that the systemic inflammatory response, myocardial 
ischemia-reperfusion injury (IRI) and surgical trauma are the primary causes of post-CPB myocardial injury $(7,8)$.

Currently, a number of drugs are used for the prevention and treatment of myocardial IRI, including calcium antagonists, $\beta$-receptor blockers and angiotensin-converting enzyme inhibitors (9-11); however, these drugs are not ideal due to side effects and safety issues (12). Recent studies have demonstrated that hydrogen-rich solution (HRS), obtained by dissolving hydrogen in physiological saline solution via special pressurization, is an effective antioxidant with a high hydrogen content, weak basicity, negative potential and low molecular water content, which balances $\mathrm{pH}$ and prevents inflammation, oxidative stress and apoptosis, and is safe and nontoxic $(13,14)$. Furthermore, HRS exerts protective effects against IRI in the brain, liver and intestine, as well as in myocardial injury; however, its underlying mechanisms of action remain unknown, which restricts its development and clinical application.

Janus-activated kinase/signal transducer and activator of transcription (JAK/STAT) signaling involves a family of important intracellular signal transduction pathways identified recently $(15,16)$. In particular, it is associated with the inflammatory response, oxidative stress, cell damage and apoptosis (17). As a crucial member of the JAK/STAT signaling pathway, JAK2/STAT3serves an important role in myocardial injury $(18,19)$. Additionally, the ischemic preconditioning, ischemic post-conditioning and anti-myocardial IRI effects of a number of drugs have been associated with activation of the JAK2/STAT3 pathway (20-22). Terrell et al (23) demonstrated that interleukin (IL)-6, an inflammatory cytokine, stimulates cardiac hypertrophy through activation of the JAK/STAT pathway; however, whether HRS protects various organs against $\mathrm{CPB}$-induced injury and whether its mechanism is associated with the JAK2/STAT3 signaling pathway have been scarcely investigated. In the present study, a CPB model was established in rats and treated with HRS, with the aim of investigating the effects of HRS on CPB-induced myocardial injury and the regulation of JAK2/STAT3 signaling. The data may provide a theoretical basis for the mechanism of perioperative organ injury and for subsequent protection strategies.

\section{Materials and methods}

\section{In vivo}

Animals and experimental protocols. A total of 30 male Sprague Dawley (SD) rats, weighing 350-400 g, aged 10 weeks old were provided by the Animal Center of China Medical University, Shenyang, China [production license no. SCXK (Liao)-2013-0001, application license no. SYXK (Liao)-2013-0007]. The present study was approved by the China Medical University Laboratory Animal Welfare and Ethics Committee. The experimental animals were fed in a barrier system and managed by experimental animal professionals. Animals were housed at a constant temperature $\left(22 \pm 1^{\circ} \mathrm{C}\right)$, with $50 \%$ humidity, and a 12 -h light-dark cycle. The rats had ad libitum access to food and autoclaved water. The experimental rats were randomly divided into a Sham group, a CPB group, and $\mathrm{aCPB}$ and HRS group ( $\mathrm{n}=10$ rats/group). Animals in the Sham group were subjected to a thoracotomy only. CPB was established in rats in the CPB group, while the rats in the CPB and HRS group were administered with an intraperitoneal injection of $6 \mathrm{ml} / \mathrm{kg}$ HRS [Prepared as previously reported (24)] three days prior to CPB. The rats were sacrificed by exsanguination from the abdominal aorta.

Establishment of CPB rat models. Rats were fasted for $6 \mathrm{~h}$ prior to surgery, with ad libitum access to water. Following being anesthetized with $2 \%$ sodium pentobarbital (Beijing Huayehuanyu Chemical Co., Ltd, Beijing, China), a tracheal intubation was established with a $16 \mathrm{G}$ trocar, and the rats were ventilated with a small animal anesthesia machine and ventilator (HX-100E; Shanghai Xinman Scientific Equipment Co., Ltd., Shanghai, China; http://www.shanghaixinman.qianyan. biz/). A $24 \mathrm{G}$ trocar was subsequently inserted into the right femoral vein to open an accessory venous pathway, and a $22 \mathrm{G}$ trocar was inserted into the left femoral artery and connected to a monitor to measure the arterial blood pressure. Another $22 \mathrm{G}$ trocar puncture catheter was used to perfuse the artery for extracorporeal circulation. A jugular internal venous catheter (18G needle with porous plug) connected to the right atrium served as a CPB drainage terminal. Fig. 1 demonstrates the extracorporeal circulation pattern, which was established in our previous study (25). For establishment of the CPB model, the following equipment connected to a PVC tube (internal diameter, $1.6 \mathrm{~mm}$ ) was applied: A venous drainage tube, blood reservoir, arterial infusion tube, filter and connecting pipe. A total of $15 \mathrm{ml}$ circulating prefilled solution (used for extracorporeal circulation) consisting of $6 \mathrm{ml}$ hydroxyethyl starch, $6 \mathrm{ml}$ lactate Ringer's solution, $1 \mathrm{ml}$ heparin $(250 \mathrm{IU} / \mathrm{kg}$ ), $5 \%$ sodium bicarbonate and $1 \mathrm{ml} 20 \%$ mannitol. At the start of the CPB, mechanical ventilation was terminated and the CPB flow rate was $>80 \mathrm{ml} / \mathrm{kg} / \mathrm{min}$; the circulation volume was maintained to ensure the flow rate and the flow time was $60 \mathrm{~min}$. During CPB, 1:4 oxygen: air mixture was ventilated through the lungs at a rate of $800 \mathrm{ml} / \mathrm{min}$, mechanical ventilation was restarted prior to the reduced flow and the circulation volume was gradually decreased by adjusting the diameter of the venous outflow end. Subsequently, the right internal jugular vein and caudal artery were ligated, followed by the removal of the catheter and suture of the incision. After spontaneous breathing resumed in the rats, the tracheal intubation was removed and the rats were maintained in the laboratory for observation.

Hemodynamic measurements. An automatic biochemical analyzer(BS-180, Shenzhen Mindray, Bio-Medical Electronics Co., Ltd., Shenzhen, China) was used to determine the $\mathrm{K}^{+}$ concentration in the serum. The main carotid artery intubation was connected to a RM6240 multichannel physiological monitor (Chengdu Instrument Factory, Chengdu, China) to measure the mean arterial pressure (MAP) and heart rate $(\mathrm{HR})$ of the rats. Changes in the blood $\mathrm{pH}, \mathrm{PaO}_{2}, \mathrm{PaCO}_{2}$ and base excess $(\mathrm{BE})$ of the rats were analyzed using a bayer-248 blood gas analyzer (Bayer AG, Leverkusen, Germany).

Histopathological changes. At $24 \mathrm{~h}$ after CPB, the rats were anesthetized with $2 \%$ pentobarbital sodium (40 mg/kg, Beijing Huayehuanyu Chemical Co., Ltd, intraperitoneal injection) and euthanized via exsanguination from the abdominal aorta. Subsequently, myocardial tissues were harvested and fixed with $10 \%$ neutral formalin at room temperature for $48 \mathrm{~h}$. Following 


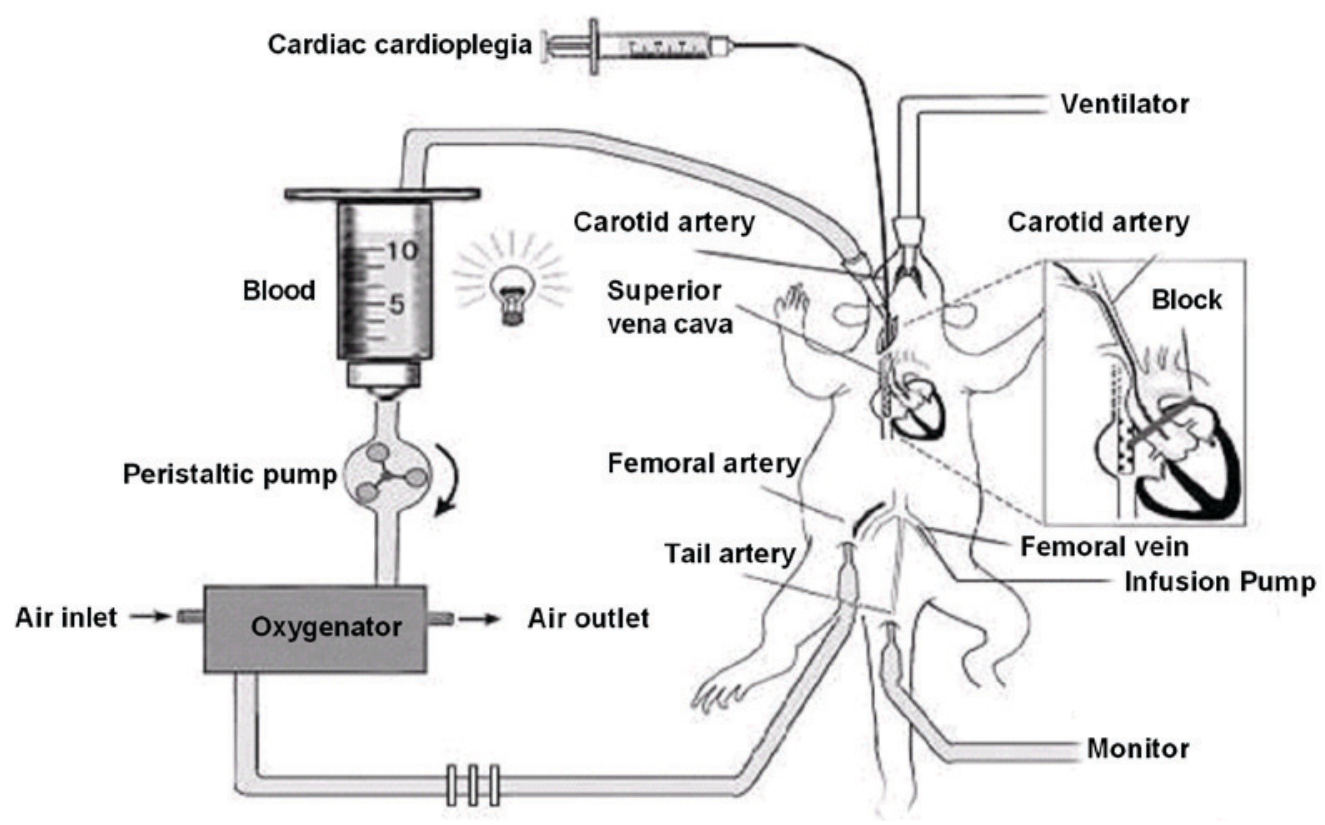

Figure 1. Establishment of the cardiopulmonary bypassrat model.

$48 \mathrm{~h}$, specimens were dehydrated with 70, 80, 90, 95 and $100 \%$ ethanol and cleared with xylene, embedded in paraffin and sliced into sections and heating at $42^{\circ} \mathrm{C}$. All of the following steps were carried out at room temperature. Subsequently, the sections were deparaffinized, transferred to xylene and hydrated with absolute ethanol for $5 \mathrm{~min}, 90 \%$ ethanol for $2 \mathrm{~min}$ and $70 \%$ ethanol for $2 \mathrm{~min}$, prior to staining with hematoxylin for $3 \mathrm{~min}$ and differentiation with $0.3 \%$ hydrochloric acid $(0.3 \mathrm{ml}$ hydrochloric acid and $100 \mathrm{ml} 70 \%$ ethanol) for another $30 \mathrm{sec}$. The sections were then diluted with $1 \%$ aqueous ammonia for $1 \mathrm{~min}$ and counterstained with $0.5 \%$ eosin solution for $1 \mathrm{~min}$ at room temperature. The sections were washed with distilled water following each step. Following staining, the sections were dehydrated, rinsed, cleared with xylene and mounted, and pathological changes in the myocardial tissue were observed via light microscopy (magnification, x200).

Myocardial Masson staining. The following steps were carried out at room temperature. Heart tissues were fixed using $10 \%$ formaldehyde for $24 \mathrm{~h}$. Paraffin-embedded sections $(5-\mu \mathrm{m}$ thick) were dewaxed using 50\% xylene for $1 \mathrm{~h}$ and $100 \%$ xylene for $2 \mathrm{~h}$, and washed with distilled water, prior to being stained with Regaud hematoxylin dye with Masson (Beijing Solarbio Science \& Technology Co., Ltd., Beijing, China) for 5-10 min. Following washing with distilled water, the sections were stained with Ponceau Fuchsin Acid solution (cat no. G1338; Solarbio, Beijing, China) for 5-10 min, soaked in $100 \mathrm{ml} \mathrm{2 \%}$ acetic acid aqueous solution (Sinopharm Chemical Reagent Co., Ltd., China), differentiated in $1 \%$ phosphomolybdic acid aqueous solution for 3-5 min and washed with aniline blue for $5 \mathrm{~min}$. The sections were subsequently immersed in $0.2 \%$ acetic acid aqueous solution, dehydrated with $95 \%$ anhydrous alcohol, cleared with xylene and sealed with neutral gum.

ELISA detection of myocardial injury markers, inflammatory cytokines and oxidative stress markers in the serum. The blood extracted from the rats were separated by centrifugation at $1,000 \mathrm{x} \mathrm{g}$ for $10 \mathrm{~min}$ at $4^{\circ} \mathrm{C}$ to make the serum. Changes in the levels of markers of myocardial injury [cardiac troponins (cTnI), heart-type fatty acid binding protein (hFABP)], inflammatory cytokines [interleukin (IL)-1, IL-6, tumor necrosis factor (TNF)- $\alpha$ ] and oxidative stress [superoxide dismutase (SOD), myocardidialdehyde (MDA) and myeloperoxidase(MPO)] were detected using ELISA kits for cTnI (cat. no. SEA478Ra; USCN Business Co., Ltd., Wuhan, China), hFABP (cat. no. SEB243Ra; USCN Business Co., Ltd.), IL-1 (cat. no. SEA563Ra; USCN Business Co., Ltd.), IL-6 (cat. no. SEA079Ra; USCN Business Co., Ltd.), TNF- $\alpha$ (cat. no. SEA133Ra; USCN Business Co., Ltd.), SOD (cat. no. SES134Ra; USCN Business Co., Ltd.), MDA (cat. no. CEA597Ge; USCN Business Co., Ltd.) and MPO (cat. no. SEA601Ra; USCN Business Co., Ltd.). Following equilibration of all reagents to room temperature $\left(20-25^{\circ} \mathrm{C}\right)$, $100 \mu 1$ standard and diluted samples (diluted with PBS; SOD, 1,000 fold dilution; MPO, 10 fold dilution; all others, 5 fold dilution) were added to separate wells in the reaction plates, with gentle agitating for $30 \mathrm{sec}$ and incubation at $20-25^{\circ} \mathrm{C}$ for $20 \mathrm{~min}$. Serum samples $(100 \mu \mathrm{l})$ were then added to each well of the reaction plate and incubated at $37^{\circ} \mathrm{Cfor} 2 \mathrm{~h}$. Subsequently, $100 \mu$ l HRP-labeled antibody (included the ELISA kit) was added to each well and incubated at $37^{\circ} \mathrm{C}$ for $30 \mathrm{~min}$. Following washing (20X washing buffer included the ELISA kit), $50 \mu 1$ each of color liquids A and B (provided by the ELISA kit) were added for development and the reaction was terminated with $50 \mu \mathrm{l}$ stop solution (provide by the ELISA kit). The optical density (OD) at $450 \mathrm{~nm}$ was measured with a microplate reader. A standard curve was plotted by taking the OD value as the ordinate and the standard sample concentration as the abscissa, from which the curve equation and R-value were calculated, thereby enabling the sample concentration to be determined.

Western blot analysis of B-cell lymphoma 2 (Bcl-2), $B c l$-2-associated X protein (Bax), JAK2 and STAT3 protein 
expression in the myocardial tissue. The myocardial tissue was ground and centrifuged in a pre-chilled RIPA buffer (Beijing Solarbio Science \& Technology Co., Ltd.) at 16,000 x g for $30 \mathrm{~min}$ at $4^{\circ} \mathrm{C}$. The supernatant was collected and protein quantification was performed by BCA (cat. no. 23230; Pierce; Thermo Fisher Scientific, Inc., Waltham, MA, USA) The supernatant of the total protein $(40 \mu \mathrm{g})$ was extracted and separated by $12 \%$ SDS-PAGE, following which the protein was semi-dried to polyvinylidene difluoride membrane transfer. The membranes were blocked for $2 \mathrm{~h}$ at room temperature in TBS with 20\% Tween-20 (TBST) buffer and incubated overnight at $4^{\circ} \mathrm{C}$ with antibodies against Bcl-2 (1:500, cat. no. ab196495; Abcam, Cambridge, MA, USA), Bax (1:1,000, cat. no. ab32503; Abcam), JAK2 (1:5,000, cat. no. ab108596; Abcam), phosphorylated-JAK2 (p-JAK2) (1:1,000, cat. no. ab32101; Abcam), STAT3 (1:1,000, cat. no. ab68153; Abcam), p-STAT3 (1:2,000; cat. no. ab76315; Abcam) and GAPDH (1:10,000; cat. no. ab181602; Abcam), followed by three washes and incubation with horseradish peroxidase conjugated Goat Anti-Rabbit IgG H\&L (HRP)(1:2,000, cat. no. ab6721; Abcam) for $1 \mathrm{~h}$ at $4^{\circ} \mathrm{C}$. Following four washes with TBST [Beijing Solarbio Science \& Technology Co., Ltd.) with 20\% Tween-20 (cat. no. T8220; Beijing Solarbio Science \& Technology Co., Ltd.)], the membranes were developed with an enhanced chemiluminescence kit (Pierce $^{\text {TM }}$ ECL Plus Western Blotting Substrate; cat no. 32132; Thermo Fisher Scientific, Inc,) and visualized with a Gel Doc ${ }^{\mathrm{TM}}$ EZ System (cat. no. 1708270; Bio-Rad Laboratories, Inc., Hercules, CA, USA). The gray values were measured with Image $\mathrm{Lab}^{\mathrm{TM}}$ software (version 6.0; Bio-Rad Laboratories, Inc.).

\section{In vitro assays}

Primary culture of neonatal rat cardiomyocytes. A total of 3 SD rats (2 male and 1 female, provided by the Animal Center of China Medical University, Shenyang, China), weighing 350-400 g, aged 10 weeks old, were placed in mating cages at a 2:1 male-female mating ratio. Animals were housed at a constant temperature $\left(22 \pm 1^{\circ} \mathrm{C}\right)$, with $50 \%$ humidity, and a 12-h light-dark cycle. The rats had ad libitum access to food and autoclaved water. A total of $24 \mathrm{~h}$ after spontaneous delivery, newly born rats were sacrificed by cervical dislocation and their chest regions were shaved and disinfected with $75 \%$ ethanol. After the thoracic skin was cut with ophthalmic scissors, heart samples were harvested and washed twice with Hank's solution (Beijing Solarbio Science \& Technology Co., Ltd.). Myocardial tissue was peeled away and placed in sterilized glass plates on ice; any attached tissue and blood cells were removed by repeated rinsing with serum-free Dulbecco's modified Eagle's medium (DMEM)/F12 culture medium (cat. no. 12400024; Gibco; Thermo Fisher Scientific, Inc.). Subsequently, myocardial tissue was cut into $2 \mathrm{~mm}$ sections, digested with $0.5 \%$ trypsin in a $50 \mathrm{ml}$ glass tube at $37^{\circ} \mathrm{C}$ for $10 \mathrm{~min}$ and oscillated $1-2$ times. To terminate digestion, the samples were mixed with twice the volume of fetal bovine serum (FBS; CLARK Bioscience, Richmond, VA, USA) for $5 \mathrm{~min}$. Subsequently, the cell suspension was filtered through a 200-mesh copper mesh to remove large tissue segments and then centrifuged at $110 \mathrm{x} g$ for $10 \mathrm{~min}$ at room temperature. The cell supernatant was discarded and the cells were suspended with DMEM/F12 medium containing
$20 \%$ FBS. Following counting and trituration, the cells were seeded into 12-well culture plates precoated with type I rat tail collagen (Beijing Solarbio Science \& Technology Co., Ltd.) at a density of $1 \times 10^{5}$ cells $/ \mathrm{ml}$. Arabinose (20 $\mu \mathrm{l}$, Beijing Solarbio Science \& Technology Co., Ltd.) was then added to each well and the cells were cultured at $37^{\circ} \mathrm{C}$ in a $5 \% \mathrm{CO}_{2}$ incubator. After $24 \mathrm{~h}$, half of the culture medium was replenished with DMEM/F12 medium containing 10\% FBS, and after another $72 \mathrm{~h}$, the culture medium was replenished with DMEM (Beijing Solarbio Science \& Technology Co., Ltd.). Subsequently, the culture medium was changed every three days and cell proliferation was observed every $24 \mathrm{~h}$ under an inverted microscope (x40, magnification).

Establishment of hypoxia-reoxygenation model and grouping. A hypoxic solution (Consisted of $137 \mathrm{mM} \mathrm{NaCl}, 12 \mathrm{mM} \mathrm{KCl}$, $0.49 \mathrm{mM} \mathrm{MgCl}_{2}, 0.9 \mathrm{mM} \mathrm{CaCl}_{2}-2 \mathrm{H}_{2} \mathrm{O}, 4 \mathrm{mM}$ HEPES, $10 \mathrm{mM}$ deoxyglucose, $0.75 \mathrm{mM}$ sodium sulfite and $20 \mathrm{mM}$ sodium lactate, $\mathrm{pH}$ 6.5) was used to simulate CPB-induced hypoxia in myocardial cells. During the hypoxia procedure, the cells were placed in $95 \% \mathrm{~N}_{2}$ and $5 \% \mathrm{CO}_{2}$ for $2 \mathrm{~h}$ at $37^{\circ} \mathrm{C}$. During the reoxygenation process, the cells were placed in a normal DMEM culture medium (cat. no. 31600; Beijing Solarbio Science \& Technology Co., Ltd.) and incubated in $95 \% \mathrm{O}_{2}$ and $5 \% \mathrm{CO}_{2}$ for $4 \mathrm{~h}$ at $37^{\circ} \mathrm{C}$.

Prior to establishment of the hypoxia-reoxygenation model, myocardial cells were divided into a hypoxia-reoxygenation group (CPB group), a control siRNA (sense, 5'-GCGUUC UGGUCUUACUGUUU-3'; antisense, 5'-AGAGAAUAAACC CGCAGACUU-3'; $20 \mu \mathrm{g}$ at $1 \mathrm{mg} / \mathrm{ml}$ ), HRS and CPB group, a JAK2 siRNA, HRS and CPB group and a JAK2 siRNA and CPB group. Cells in the siRNA groups were transfected with JAK2 or control siRNA prior to hypoxia-reoxygenation. The cells were inoculated into 6-well culture plates at a density of $2 \times 10^{5}$ cells/well with high-glucose DMEM and incubated in a $\mathrm{CO}_{2}$ incubator for $24 \mathrm{~h}$ at $37^{\circ} \mathrm{C}$. Transfection medium $(100 \mu \mathrm{l}$, cat. no. 31985062, Opti-MEM ${ }^{\mathrm{TM}}$, Thermo Fisher Scientific, Inc.) mixed with 20-80 pM JAK2/control siRNA was taken as solution A and $100 \mu \mathrm{l}$ transfection medium mixed with 2-8 $\mu \mathrm{l}$ siRNA Lipofectamine ${ }^{\circledR} 2000$ transfection reagent (Invitrogen; Thermo Fisher Scientific, Inc.) was taken as solution B. Solution $\mathrm{A}$ and solution $\mathrm{B}$ were mixed and left for $45 \mathrm{~min}$ and cells were rinsed with $2 \mathrm{ml}$ siRNA transfection medium (Thermo Fisher Scientific, Inc.). siRNA transfection medium $(0.8 \mathrm{ml})$ was then added to the mixture of $\mathrm{A}$ and $\mathrm{B}$, which was administered to cells in a $\mathrm{CO}_{2}$ incubator for $7 \mathrm{~h}$ at $37^{\circ} \mathrm{C}$, for siRNA transfection. The cells were subjected to hypoxia-reoxygenation and used in subsequent assays $24 \mathrm{~h}$ after transfection. In the HRS groups, cells were treated with $0.8 \mathrm{mM} / 1 \mathrm{HRS}$ during the $2 \mathrm{~h}$ hypoxia stage and then reoxygenated for $4 \mathrm{~h}$.

Determination of cell viability by MTT colorimetry. The cells in the logarithmic growth phase were inoculated into 96-well culture plates at a density of 2,000-5,000/well (100 $\mu \mathrm{l}$ cells/well). Next, $20 \mu 15 \mathrm{mg} / \mathrm{ml}$ MTT solution (cat no. V13154; Thermo Fisher Scientific, Inc.) was added to each well and the cells were cultured for $4 \mathrm{~h}$ at $37^{\circ} \mathrm{C}$, following which the supernatant was removed and $150 \mu \mathrm{l}$ dimethyl sulfoxide was added to each well. Cells were agitated for $10 \mathrm{~min}$ to dissolve the crystals and then the OD at $570 \mathrm{~nm}$ was measured with 
Table I. MAP, HR, RT and blood gasanalysis at each time point.

\begin{tabular}{|c|c|c|c|c|c|}
\hline & Prior to $\mathrm{CPB}$ & Block the aorta & Open the aorta & CPB $60 \mathrm{~min}$ & Stop CPB $2 \mathrm{~h}$ \\
\hline Variable & $\mathrm{T}_{0}$ & $\mathrm{~T}_{1}$ & $\mathrm{~T}_{2}$ & $\mathrm{~T}_{3}$ & $\mathrm{~T}_{4}$ \\
\hline MAP, mmHg & $86.35 \pm 7.52$ & $30.38 \pm 2.21^{\mathrm{a}}$ & $60.16 \pm 12.35^{\mathrm{a}}$ & $65.38 \pm 14.13^{\mathrm{a}}$ & $80.19 \pm 17.39$ \\
\hline HR, bpm & $330 \pm 28$ & $0^{\mathrm{a}}$ & $200 \pm 24^{a}$ & $280 \pm 31^{\mathrm{a}}$ & $310 \pm 35$ \\
\hline $\mathrm{RT},{ }^{\circ} \mathrm{C}$ & $36.21 \pm 1.53$ & $34.37 \pm 0.82^{\mathrm{a}}$ & $35.81 \pm 1.16$ & $36.53 \pm 0.95$ & $36.58 \pm 1.42$ \\
\hline $\mathrm{pH}$ & $7.40 \pm 0.05$ & $7.36 \pm 0.04$ & $7.32 \pm 0.03$ & $7.35 \pm 0.03$ & $7.36 \pm 0.05$ \\
\hline $\mathrm{PaO}_{2}, \mathrm{mmHg}$ & $300 \pm 21$ & $280 \pm 15$ & $290 \pm 23$ & $300 \pm 30$ & $310 \pm 28$ \\
\hline $\mathrm{PaCO}_{2}, \mathrm{mmHg}$ & $38.56 \pm 2.23$ & $36.98 \pm 4.05^{\mathrm{a}}$ & $37.63 \pm 3.32$ & $36.58 \pm 2.58$ & $35.43 \pm 2.40$ \\
\hline $\mathrm{BE}, \mathrm{mmol} / \mathrm{l}$ & $-1.51 \pm 0.55$ & $-2.04 \pm 0.60$ & $-2.53 \pm 0.85$ & $-3.05 \pm 1.74$ & $-3.08 \pm 1.51$ \\
\hline HCT & $0.40 \pm 0.05$ & $0.21 \pm 0.03^{\mathrm{a}}$ & $0.20 \pm 0.03^{\mathrm{a}}$ & $0.25 \pm 0.04^{\mathrm{a}}$ & $0.26 \pm 0.04^{\mathrm{a}}$ \\
\hline $\mathrm{K}^{+}, \mathrm{mmol} / \mathrm{l}$ & $4.82 \pm 0.63$ & $4.41 \pm 0.75$ & $5.24 \pm 0.95$ & $5.36 \pm 0.72$ & $5.04 \pm 0.46$ \\
\hline
\end{tabular}

${ }^{\text {aP }}<0.05$, compared with $\mathrm{T}_{0}$. CPB, cardiopulmonary bypass; MAP, mean arterial pressure; HR, heart rate; RT, rectal temperature; BE, base excess; HCT, hematocrit.

an ELISA microplate reader. The cell survival and inhibition rates were calculated as follows: Cell survival rate $=(O D$ value of the intervention group/OD value of the normal control group) $x 100$; inhibition rate $=1-O D$ value of the intervention group/OD value of the control group.

Detection of the apoptotic rate. Cell apoptosis was detected according to the instructions of an Annexin V-FITC apoptosis detection kit (Beyotime Institute of Biotechnology, Haimen, China). Myocardial cells at a density of $1 \times 10^{5}$ cells $/ \mathrm{ml}$ were inoculated into 6 -well cell culture plates $(2 \mathrm{ml}$ cells/well $)$ and incubated at $37^{\circ} \mathrm{C}$ for 2 days, until the bottom of the plates were covered. The aforementioned siRNA, hypoxia and HRS treatments were performed, and then the cells were counted, centrifuged at $1,000 \times \mathrm{g}$ for $5 \mathrm{~min}$ at room temperature and cultured with $195 \mu \mathrm{l}$ Annexin V-FITC binding solution and $5 \mu \mathrm{l}$ Annexin V-FITC for $10 \mathrm{~min}$ at room temperature. Following centrifugation, the cells were resuspended with $190 \mu \mathrm{l}$ Annexin V-FITC, stained with $10 \mu \mathrm{l}$ propidium iodide in the dark for 10-20 min at room temperature and analyzed using a flow cytometer (Attune NxTv. 2.6, Thermo Fisher Scientific, Inc.).

Protein detection by western blot analysis. Cells were ultrasonic fragmented and centrifuged in a radioimmunoprecipitation assay lysis buffer (cat no. 89901; Thermo Fisher Scientific, Inc.) at $16,000 \mathrm{xg}$ for $30 \mathrm{~min}$ at $4^{\circ} \mathrm{C}$. The total protein concentration was determined using a bicinchoninic acid kit (cat no. 23227; Thermo Fisher Scientific, Inc.). The protein levels of Bcl-2, Bax, JAK2, p-JAK2, STAT3 and p-STAT3 were measured using western blot analysis, as previously described.

Lactate dehydrogenase (LDH), SOD and MDA levels in myocardial culture medium. The culture medium of the myocardial cells was collected to measure the levels of $\mathrm{LDH}$, SOD and MDA by ELISA as previously described.

Preparation and treatment of rat tissues. All rats were anesthetized with $2 \%$ pentobarbital sodium at $24 \mathrm{~h}$ after the
CPB procedure. Blood samples $(3 \mathrm{ml})$ were collected from the internal jugular vein and the serum was separated by centrifugation at $1,000 \times \mathrm{g}$ for $10 \mathrm{~min}$ at $4^{\circ} \mathrm{C}$ and stored at $-80^{\circ} \mathrm{C}$ for measurement of serum levels by ELISA as previously described. Isolated rat myocardial tissues were fixed in $10 \%$ neutral formalin for $48 \mathrm{~h}$ at room temperature or stored in liquid nitrogen $\left(-196^{\circ} \mathrm{C}\right)$.

Statistical analysis. Measurement data are expressed as the mean \pm standard deviation and were analyzed using SPSS 19.0 statistical software (IBM Corp., Armonk, NY, USA). One-way analysis of variance (ANOVA) followed by a Tukey's post-hoc test was used to compare the differences between two groups and intra-group comparisons were performed using repeated ANOVA. $\mathrm{P}<0.05$ was considered to indicate a statistically significant difference.

\section{Results}

Changes in the hemodynamics of $C P B$ rats. As depicted by the results in Table I, the MAP, HR, rectal temperature and blood gas levels were all significantly decreased immediately following $\mathrm{CPB}$ administration $(\mathrm{P}<0.05)$ and returned to normal levels $2 \mathrm{~h}$ following CPB withdrawal. Notably, HR was lower upon opening of the aorta $(\mathrm{P}<0.05) ; \mathrm{PaCO}_{2}$ and $\mathrm{PaO}_{2}$ levels were stable prior to and following $\mathrm{CPB}$ and the values following $\mathrm{CPB}$ did not differ significantly to those at the T0 time point $(\mathrm{P}>0.05)$; hematocrit levels were significantly decreased following $\mathrm{CPB}$ $(\mathrm{P}<0.05)$; the blood $\mathrm{pH}$ value was stable following $\mathrm{CPB}$; and $\mathrm{K}^{+}$ ions remained stable during $\mathrm{CPB}$. These changes were consistent with the trends in HR, MAP and blood gases during the cardiac surgery (data not shown).

HRS alleviates pathological injury in the myocardium. Myocardial cells from the Sham group exhibited an orderly arrangement and had clear boundaries and intact nuclei. Myocardial cells from the CPB group exhibited a disorderly arrangement with indistinct boundaries, myofibre rupture and disappearance of the nuclei. In the HRS group, the severity of 
A

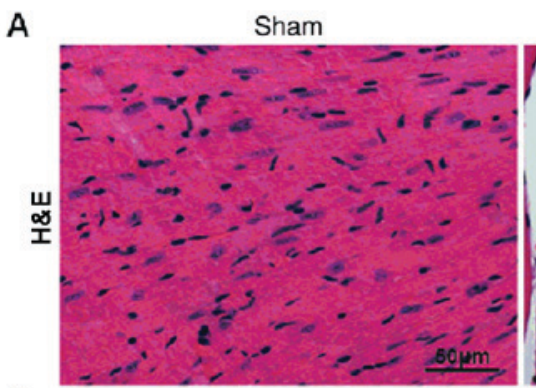

B

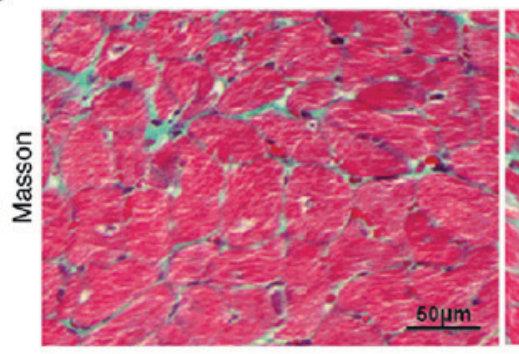

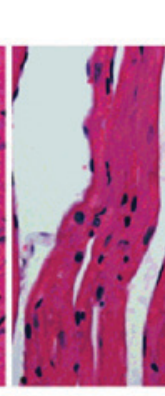

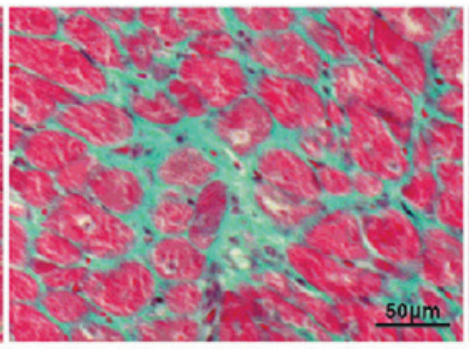

CPB

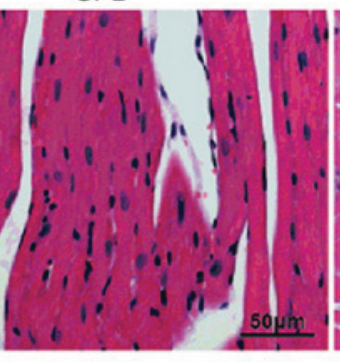

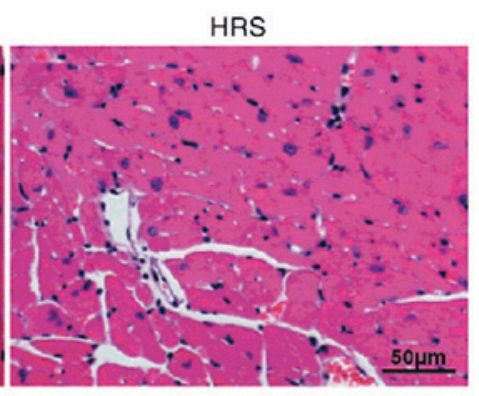

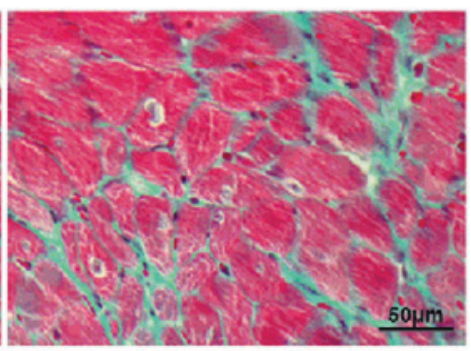

Figure 2. HRS alleviates pathological injury in the myocardium. (A) H\&E staining and (B) Masson staining were used to observe the pathological changes. There was no evidence of morphological damage in myocardial samples from the Sham group. By contrast, notable cellular degeneration and abnormal cell arrangements were observed in myocardial samples from the cardiopulmonary bypass group. Samples from the HRS group only exhibited slight morphological changes. HRS, hydrogen-rich solution; CPB, cardiopulmonary bypass; H\&E, hematoxylin and eosin.

myocardial injuries was improved, compared with the CPB group. The Masson trichrome staining results also identified myocardial fibrosis and notable damage in the myocardium of the CPB group, which was improved in the HRS group (Fig. 2).

$H R S$ reduces the serum levels of $I L-1 \beta, T N F-\alpha$ and $I L-6$ in $C P B$-injured rats. Compared with the Sham group, the serum levels of IL-1 $\beta$, IL- 6 and TNF- $\alpha$ in the CPB group were significantly increased $(\mathrm{P}<0.05)$. Compared with the $\mathrm{CPB}$ group, IL-1 $\beta$, IL- 6 and TNF- $\alpha$ levels in the HRS group were significantly decreased ( $\mathrm{P}<0.05$; Fig. 3 ).

$H R S$ reduces the levels of $c T n I$ and $h F A B P$ in $C P B$-injured rats. The levels of cTnI and hFABP in the CPB group were significantly higher, compared with the Sham group $(\mathrm{P}<0.05)$, and compared with the CPB group, the levels of cTnI and hFABP in the HRS group were significantly decreased $(\mathrm{P}<0.05$; Fig. 4).

Changes in SOD, MDA and MPO levels. The levels of MDA and MPO in the serum of the CPB group were significantly higher, compared with the Sham group, whilst the level of SOD was significantly reduced $(\mathrm{P}<0.05)$. Compared with the CPB group, the serum levels of MDA and MPO in the HRS group were significantly decreased, while the level of SOD was significantly increased $(\mathrm{P}<0.05$; Fig. 5).

Expression of Bcl-2, Bax, JAK2, p-JAK2, STAT3 and $p$-STAT3. Compared with the Sham group, the protein expression levels of Bcl-2, JAK2, p-JAK2, STAT3 and p-STAT3 in the myocardial tissues of rats in the CPB group were significantly reduced, whilst Bax expression was significantly increased $(\mathrm{P}<0.05)$. Conversely, the expression levels of Bcl-2, JAK2, p-JAK2, STAT3 and p-STAT3 in the HRS group were significantly higher, compared with the CPB group $(\mathrm{P}<0.05)$, and the expression of Bax was significantly reduced (Fig. 6).

Changes in myocardial cell viability and apoptotic rate. The viability of myocardial cells in each group was detected using the MTT method following reoxygenation. It was observed that HRS treatment significantly increased the viability of myocardial cells in the control siRNA and CPB groups following hypoxia/reoxygenation $(\mathrm{P}<0.01)$. This myocardial protective effect of HRS was attenuated by transfection with JAK2 siRNA, as indicated by a decrease in the viability of cells in the JAK2 siRNA, HRS and CPB group ( $\mathrm{P}<0.01$ vs. control siRNA, HRS and CPB groups). By contrast, compared with the control siRNA and CPB groups, cells in the JAK2 siRNA and $\mathrm{CPB}$ group exhibited no significant change in cell viability (P>0.05; Fig. 7A).

The apoptotic rates of cells were also detected by flow cytometry following reoxygenation. Compared with control siRNA and CPB treatments alone, the HRS, control siRNA andCPB treatments significantly reduced the apoptotic rate of myocardial cells following hypoxia/reoxygenation $(\mathrm{P}<0.01)$. JAK2 siRNA significantly attenuated this myocardial protective effect of HRS by increasing the apoptotic rate of myocardial cells in the JAK2 siRNA, HRS and CPB group ( $\mathrm{P}<0.01$ vs. control siRNA, HRS and CPB groups). Compared with the control siRNA and CPB groups, cells in the JAK2 siRNA and CPB group exhibited no significant change in apoptotic rate ( $\mathrm{P}>0.05$; Fig. 7B-F).

Effects of HRS and JAK2 knockdown on the release of LDH, SOD and MDA from myocardial cells following hypoxia/reoxygenation. The amounts of LDH, MDA and SOD released into the cell culture medium following reoxygenation were measured. Compared with control siRNA and CPB 
A



B





Figure 3. HRS reduces the serum levels of IL-1 $\beta$, IL- 6 and TNF- $\alpha$ in CPB-injured rats. The levels of (A) IL-1 $\beta$, (B) IL- 6 and (C) TNF- $\alpha$ were detected by ELISA. " $\mathrm{P}<0.05$ compared with the Sham group; ${ }^{* *} \mathrm{P}<0.05$ compared with the CPB group. CPB, cardiopulmonary bypass; HRS, hydrogen-rich solution; IL, interleukin; TNF, tumor necrosis factor.

A

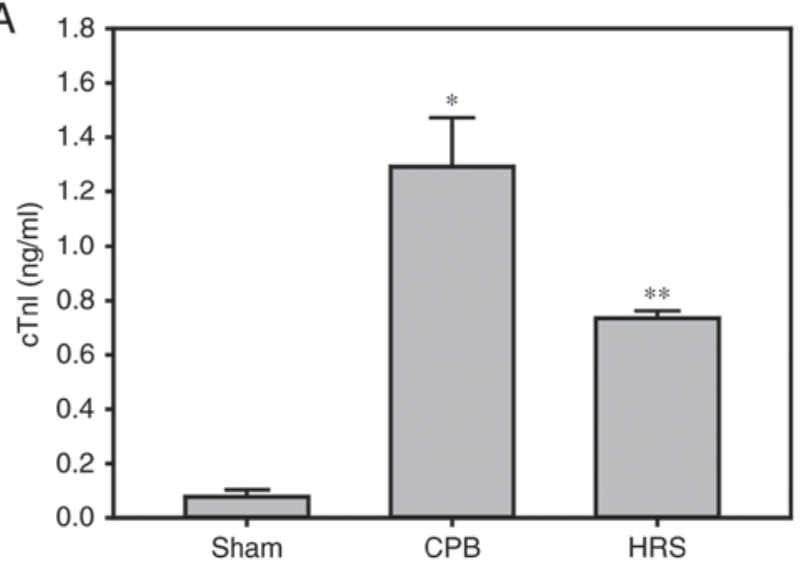

B

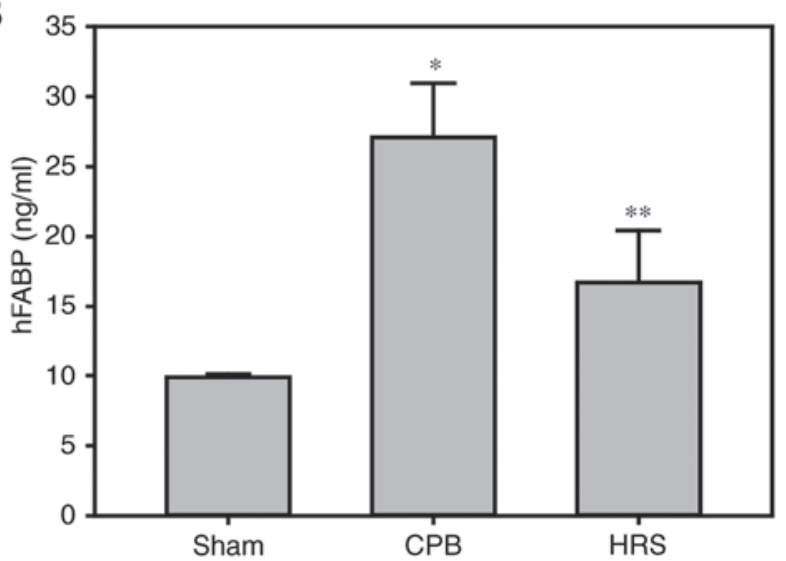

Figure 4. HRS reduces the levels of cTnI and hFABP in CPB-injured rats. The levels of (A) cTnI and (B) hFABP were detected by ELISA. "P<0.05 compared with the Sham group; ${ }^{* *} \mathrm{P}<0.05$ compared with the CPB group. $\mathrm{CPB}$, cardiopulmonary bypass; HRS, hydrogen-rich solution; cTnI, cardiac troponins; hFABP, heart-type fatty acid binding protein.
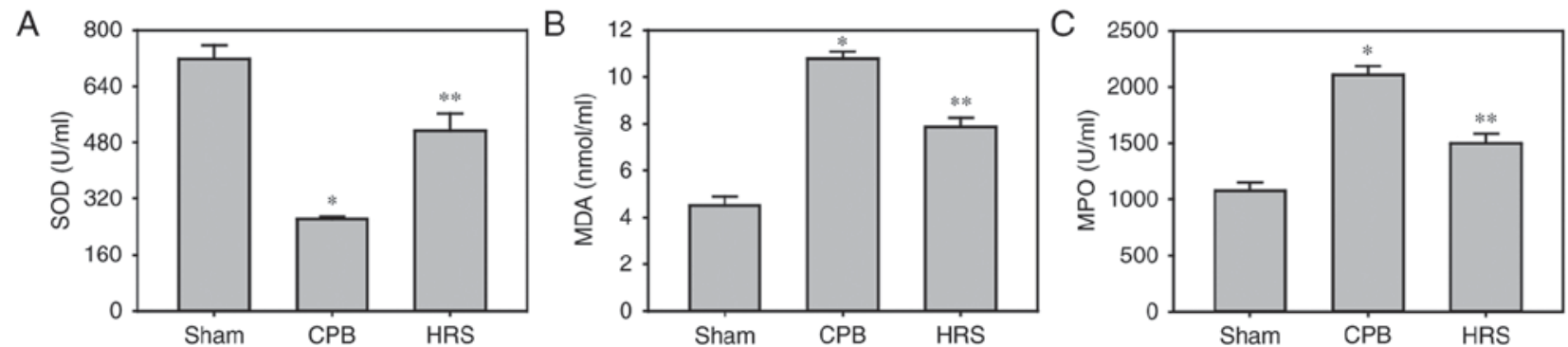

Figure 5. HRS reverses changes in the levels of SOD, MDA and MPO in CPB-injured rats. The levels of (A) SOD, (B) MDA and (C) MPO were detected by ELISA. " $\mathrm{P}<0.05$ compared with the Sham group; ${ }^{* *} \mathrm{P}<0.05$ compared with the CPB group. CPB, cardiopulmonary bypass; HRS, hydrogen-rich solution; SOD, superoxide dismutase; MDA, malonyl dialdehyde; MPO, myeloperoxidase.

treatments alone, the addition of the HRS treatment was determined to significantly decrease the release of LDH and MDA, and increase that of SOD from myocardial cells following hypoxia/reoxygenation $(\mathrm{P}<0.01)$. JAK2 siRNA reversed this protective effect of HRS, and increased the release of LDH and MDA while decreasing the release of SOD from myocardial cells in the JAK2 siRNA, HRS and CPB group $(\mathrm{P}<0.05)$. Compared with control siRNA and CPB treatments, the JAK2 siRNA and CPB treatment had no significant effect on LDH, MDA and SOD release (Fig. 8).

Effects of HRS and JAK2 knockdown on protein expression in myocardial cells following hypoxia/reoxygenation. Following hypoxia/reoxygenation, the myocardial cells were subjected to western blot analysis. Compared with the control siRNA and CPB treatments alone, the addition of the HRS treatment significantly increased the expression levels of p-JAK2, p-STAT3 and Bcl-2 following hypoxia/reoxygenation and significantly decreased Bax expression. JAK2 siRNA reversed this protective effect of HRS, and significantly decreased the expression levels of p-JAK2, p-STAT3 and Bc1-2, while significantly increasing Bax expression $(\mathrm{P}<0.05$ vs. control siRNA, HRS and CPB groups). Furthermore, the JAK2 siRNA and CPB treatment significantly reduced p-JAK2 and p-STAT3 expression, compared with the control siRNA and CPB treatments (Fig. 9). 
A



$B$

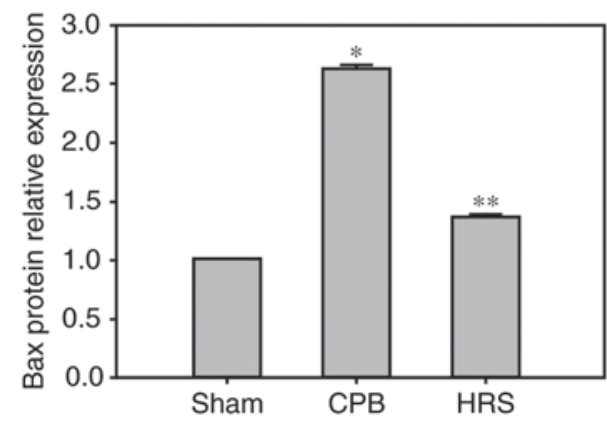

C

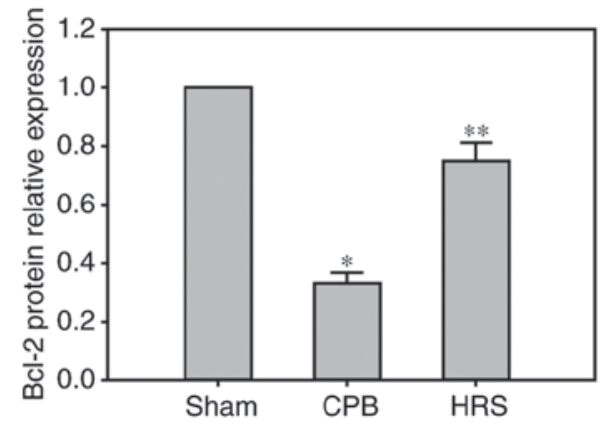

D

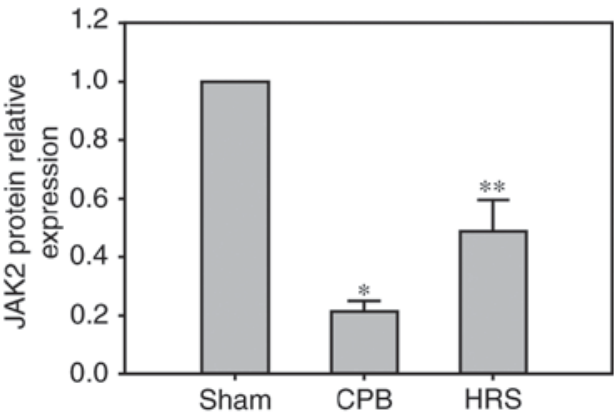

$\mathrm{F}$

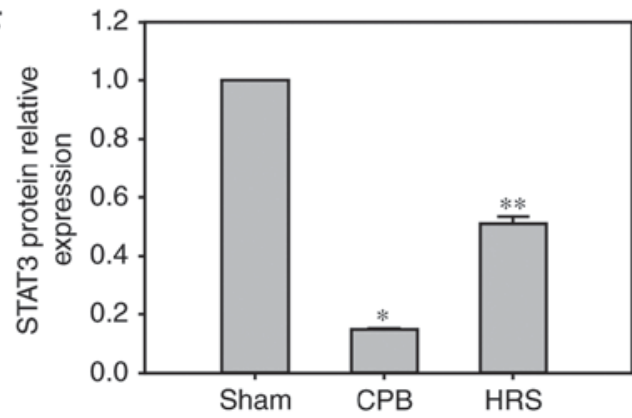

$E$



$\mathrm{G}$

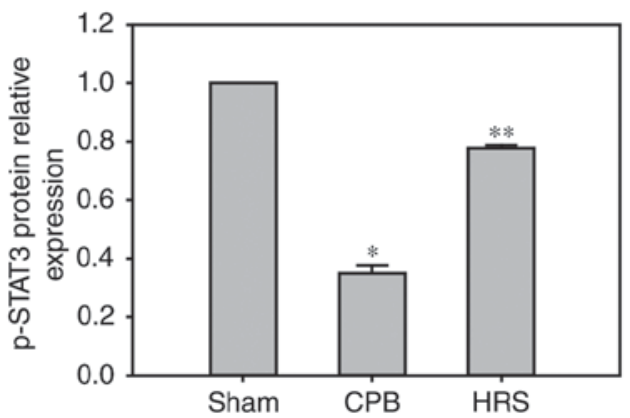

Figure 6. HRS promotes the expression of Bcl-2, JAK2, p-JAK2, STAT3 and p-STAT3. (A) Western blot analysis and quantification of the expression levels of (B) Bax, (C) Bcl-2, (D) JAK2, (E) p-JAK2, (F) STAT3 and (G) p-STAT3. Relative protein expression levels were calculated. *P<0.05 compared with the Sham group; ${ }^{* *} \mathrm{P}<0.05$ compared with the CPBgroup. CPB, cardiopulmonary bypass; HRS, hydrogen-rich solution; Bcl-2, B-cell lymphoma 2; Bax, Bcl-2-associated X protein; JAK2, Janus-activated kinase 2; p-JAK2, phosphorylated-JAK2; STAT3, signal transducer and activator of transcription 3; p-STAT3, phosphorylated-STAT3.

\section{Discussion}

In the present study, the effect of HRS on myocardial injury in CPB rats was investigated, principally by evaluating histopathological changes, the viability and apoptosis of cells, and the expression levels of Bcl-2, Bax, JAK/STAT family proteins (JAK2, STAT3) and inflammatory factors. The results demonstrated that HRS reduced CPB-induced myocardial injury, decreased the expression of inflammatory cytokines and reduced cell apoptosis. In addition, the protective effect of HRS against CPB-induced myocardial injury may have occurred via the upregulation of JAK2, p-JAK2, STAT3, p-STAT3 and $\mathrm{Bc1}-2$, and the downregulation of Bax in the myocardium.

The JAK2/STAT3 pathway serves an important role in the oxidative stress and apoptotic responses of primary culture myocardial cells, and it was observed that HRS inhibited myocardial injury by regulating the JAK2/STAT3 pathway. The incidence of complications and mortality following open-heart surgery with CPB is associated with the severity of myocardial injury that occurs during surgery $(26,27)$. As a potential therapeutic, HRS has been reported to exert anti-oxidative stress, anti-apoptotic and anti-inflammatory effects (28-30).

Due to the complexity of open-heart surgery, the processes of CPB and circulatory arrest require relatively long time periods, during which the blood supply may become blocked, leading to myocardial ischemia and hypoxia (31). After the aorta is opened, the heart is re-perfused with systemic blood flow and a large number of white blood cells accumulate in the myocardial microvascular bed and interact with inflammatory mediators, resulting in the release of oxygen free radicals and other toxic substances, which ultimately leads to ischemic injury and an enhanced systemic inflammatory response $(8,32)$. Accordingly, these events increase the incidence of postoperative malignant arrhythmia and low cardiac output syndrome. In the present study, CPB models in rats with circulatory arrest were established according to a previous study (33); the circulatory arrest and resuscitation processes are consistent with clinical practice. 
A

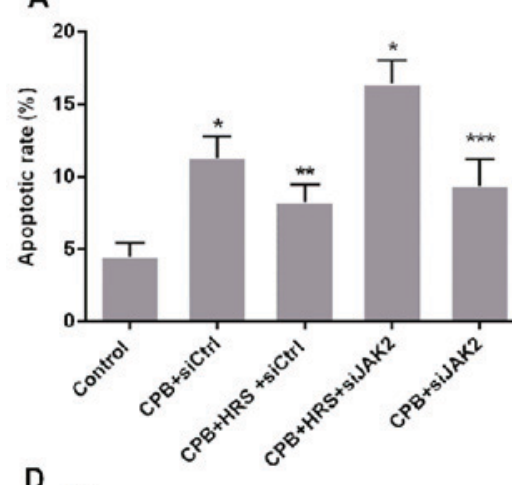

B

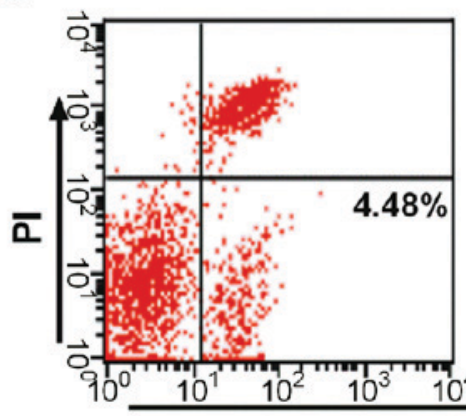

C



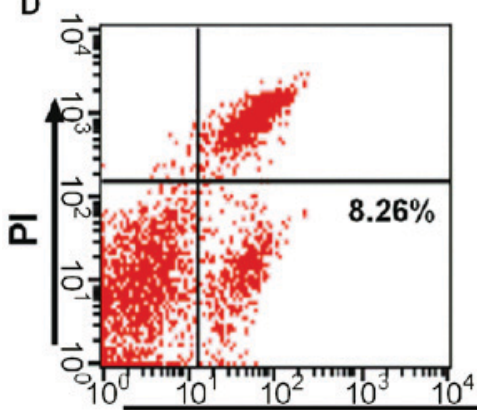

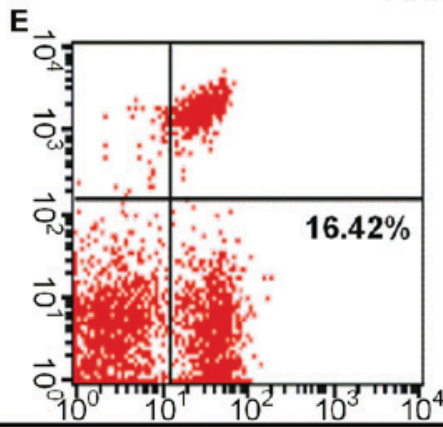

Annexin $\mathrm{V}$

$F$

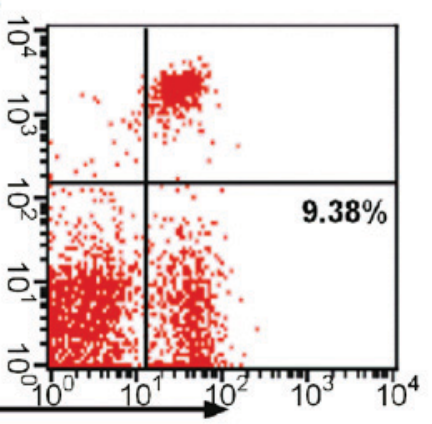

Annexin V

Figure 7. Changes in myocardial cell apoptotic rate. (A) Myocardial cell apoptotic rate. (B) Cell apoptotic rates detected by flow cytometry for control group. (C) Cell apoptotic rates detected by flow cytometry for the CPB + siCtrl group. (D) Cell apoptotic rates detected by flow cytometry for the CPB $+\mathrm{HRS}+\mathrm{siCtrl}$ group. (E) Cell apoptotic rates detected by flow cytometry for the CPB + HRS + siJAK2 group. (F) Cell apoptotic rates detected by flow cytometry for the CPB + siJAK2 group. CPB, cardiopulmonary bypass; HRS, hydrogen-rich solution; JAK2, Janus-activated kinase 2; siJAK2, small interfering-Janus-activated kinase 2; PI, propidium iodide; siCtrl, control siRNA.
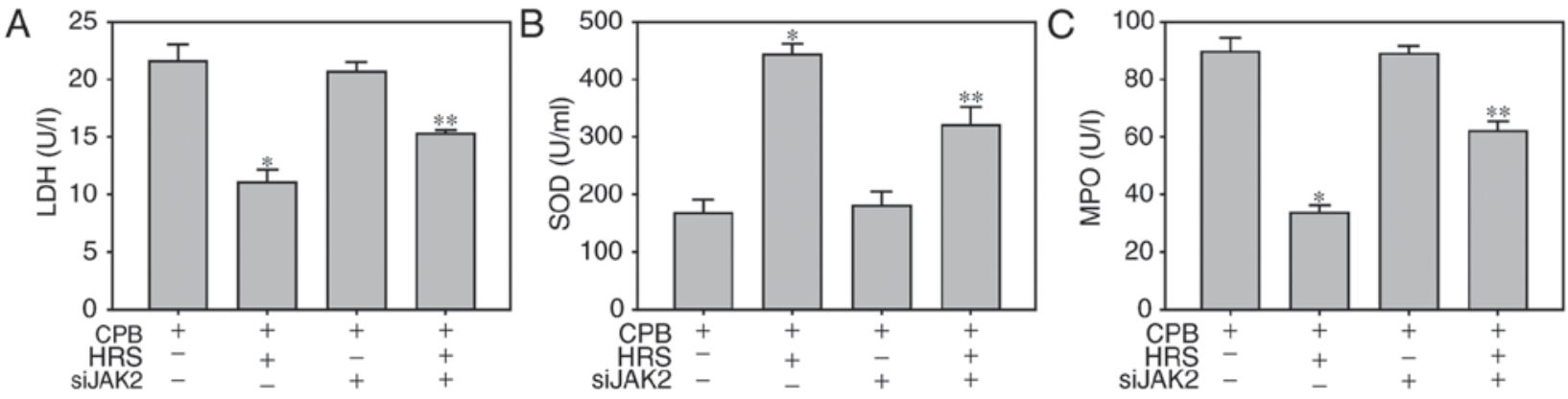

Figure 8. Effects of HRS and JAK2 knockdown on the release of LDH, SOD and MDA from myocardial cells following hypoxia/reoxygenation. The levels of (A) LDH, (B) SOD and (C) MPO were detected by ELISA. "P<0.05 compared with the control siRNA and CPB groups; ${ }^{* *} \mathrm{P}<0.05$ compared with the siRNA, HRS and CPB group. HRS, hydrogen-rich solution; CPB, cardiopulmonary bypass; siJAK2, small interfering-Janus-activated kinase 2; LDH, lactate dehydrogenase; SOD, superoxide dismutase; MPO, myeloperoxidase; JAK2, Janus-activated kinase 2.

Although there are a number of perioperative myocardial protection strategies and drugs, a number of them are not ideal myocardial protection approaches due to associated side effects and safety and ethics issues $(34,35)$. Hydrogen is an optimal natural antioxidant, and therefore hydrogen-containing solution has a strong reductive function and may neutralize free radicals within blood and cells (36). Additionally, HRS containing hydrogen dissolved in saline may enter cells, where it has the ability to become involved in metabolic pathways, and notably may promote cell detoxification, increase cell hydration and enhance the immune system (37-41). Animal experiments and clinical trials have demonstrated that HRS markedly inhibited the injuries induced by IR in the heart, liver, lung and intestine, by reducing the inflammatory response and excessive oxidation and there by protecting the organs (42-44). Furthermore, HRS may effectively reduce lung and bronchoalveolar lavage fluid, decrease the lung wet/dry weight ratio and significantly inhibit TNF- $\alpha$, IL-6, IL-1 $\alpha$ and VCAM-1 mRNA expression in rats (45). In the present study, it was demonstrated that HRS improved CPB-induced myocardial injury, reduced cTnI, hFABP, IL- $1 \beta$, IL-6, TNF- $\alpha$, MDA and MPO expression levels, enhanced SOD release and inhibited apoptotic protein expression. These data indicated that HRS protected against the CPB-induced myocardial injury in the rat model, and that this protective effect was achieved through anti-inflammatory and anti-apoptotic effects.

JAK2/STAT3 signal transduction pathways serve an important role in various pathophysiological processes in the 

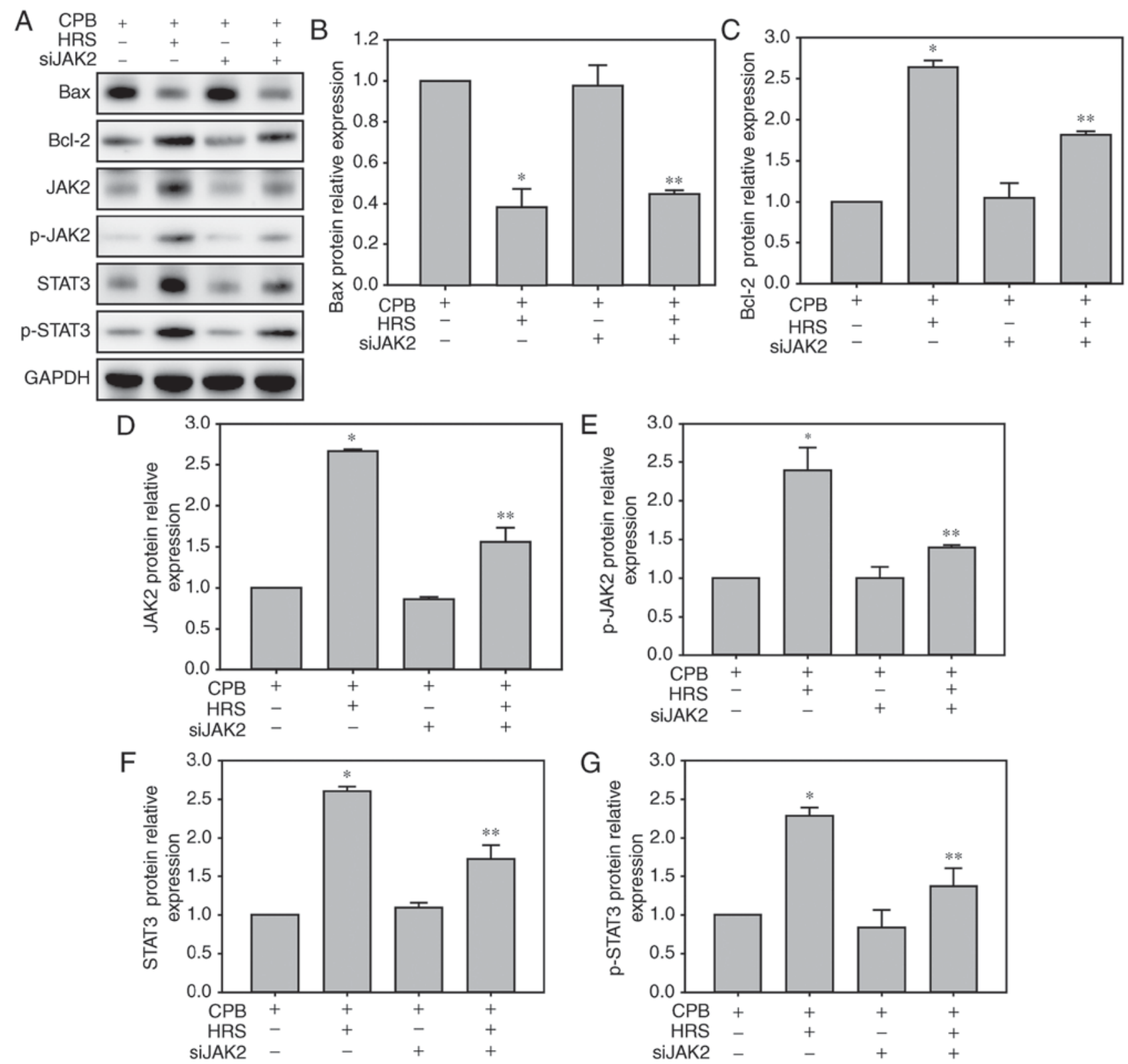

Figure 9. Effects of HRS and JAK2 knockdown on protein expression in myocardial cells following hypoxia/reoxygenation. (A) Western blot analysis and quantification of the expression levels of (B) Bax, (C) Bcl-2, (D) JAK2, (E) p-JAK2, (F) STAT3 and (G) p-STAT3. "P<0.05 compared with the control siRNA and CPB group; ${ }^{* *} \mathrm{P}<0.05$ compared with the siRNA, HRS and CPB group. HRS, hydrogen-rich solution; CPB, cardiopulmonary bypass; Bcl-2, B-cell lymphoma 2; JAK2, Janus-activated kinase 2; p-JAK2, phosphorylated-JAK2; STAT3, signal transducer and activator of transcription 3; p-STAT3, phosphorylated-STAT3; siJAK2, small interfering JAK2.

cardiovascular system (46).JAK2 may be activated by autophosphorylation, and activated JAK2 may recruit and phosphorylate STAT3 on one or more receptor sites to induce its activation and dissociation, which enables JAK2 to exert cardioprotective effects via STAT3 (47). Hilfiker-Kleiner et al (48) demonstrated that myocardial infarcted areas in myocardium-specific STAT3 knockout mice following IRI intervention were larger and exhibited a greater amount of apoptotic cells than that in wild-type mice and were associated with a higher mortality rate. The anti-IRI effects of numerous drugs and factors involve the activation of the of JAK2/STAT3 pathway $(20,49)$. Li et al (50) demonstrated that fasudil exerted protective effects on rat myocardium following ischemia by inhibiting endoplasmic reticulum stress and activating the JAK2/STAT3 pathway. According to the data of Luan et al (51), hydrogen sulfide post-conditioning also protected the myocardium via the JAK2/STAT3 pathway during myocardial IR. In the present study, the expression levels of Bcl-2, JAK2, p-JAK2, STAT3 and p-STAT3 in rat myocardium were significantly decreased following CPB, and HRS increased the expression levels of these proteins in the JAK2/STAT3 pathway. These data indicated that the JAK2/STAT3 pathway serves an important role in CPB-induced myocardial injury.

Previous studies have reported that STAT3 may protect myocardial cells, and that activated STAT3 may inhibit the apoptosis of normal myocardial cells upon injury $(52,53)$. By contrast, the anti-apoptotic effects of STAT3 in tumor cells may contribute to tumor growth $(54,55)$. Tao et al $(56)$ measured 
cardiac function in rats by echocardiography $8 \mathrm{~h}$ after injections of LPS and/or HRS, and observed that the addition of HRS increased fractional shortening and the ratio of phosphocreatinine to ATP. Furthermore, the potential inhibition of JNK by HRS had beneficial effects in the LPS-challenged rats, by restoring cardiac fatty acid oxidation (56). To further investigate the underlying mechanism of the JAK2/STAT3 pathway regarding myocardial IRI, cultured myocardial cells were subjected to hypoxia and reoxygenation and JAK2 siRNA was used to specifically block the JAK2/STAT3 pathway. The results demonstrated that HRS treatment significantly increased the viability and decreased the apoptosis of myocardial cells, elevated SOD levels, decreased the release of MDA and LDH, upregulated the expression levels of p-JAK2, p-STAT3 and the anti-apoptotic protein Bcl-2, and downregulated the expression of the apoptosis-associated protein Bax following hypoxia/reoxygenation. Therefore, HRS had a clear myocardial protective effect and inhibited apoptosis, which was probably mediated through regulation of the JAK2/STAT3 pathway.

In summary, the JAK2/STAT3 signaling pathway serves an important role in the mechanism of CPB-induced myocardial injury, and HRS may alleviate CPB-induced oxidative stress injury and apoptosis through the JAK2/STAT3 signaling pathway, thereby exerting protective effects.

\section{Acknowledgements}

Not applicable.

\section{Funding}

The present study was supported by the Natural Science Foundation of China (grant nos. 81471121 and 31601005), Liaoning natural fund project (grant no. 2016028020) and the New Teacher Foundation of China Medical University (grant no. XZR20160036).

\section{Availability of data and materials}

The datasets used and/or analyzed during the current study are available from the corresponding author on reasonable request.

\section{Authors' contributions}

$\mathrm{KC}$ and WD conceived and designed the study, acquired data, interpreted the results and drafted the manuscript. WD also contributed to the acquisition of funding and support. $\mathrm{KC}$, YS and YD performed the experiments. TZ analyzed the data. All authors read and approved the final manuscript.

\section{Ethics statement and consent to participate}

The present study was approved by the China Medical University Laboratory Animal Welfare and Ethics Committee.

\section{Consent for publication}

Not applicable.

\section{Competing interests}

The authors declare that they have no competing interests.

\section{References}

1. Zhang J and Wang S: Effects of sevoflurane on cardiopulmonary function in patients undergoing coronary artery bypass. J Biol Regul Homeost Agents 30: 1079-1083, 2016.

2. Gao H, Zhu B, Yi J, Ye TH and Huang YG: Urgent tracheal resection and reconstruction assisted by temporary cardiopulmonary bypass: A case report. Chin Med Sci J 28: 55-57, 2013.

3. Narducci ML, Pelargonio G, Rio T, Leo M, Di Monaco A, Musaico F, Pazzano V, Trotta F, Liuzzo G, Severino A, et al: Predictors of postoperative atrial fibrillation in patients with coronary artery disease undergoing cardiopulmonary bypass: A possible role for myocardial ischemia and atrial inflammation. J Cardiothorac Vasc Anesth 28: 512-519, 2014.

4. Suleiman MS, Zacharowski K and Angelini GD: Inflammatory response and cardioprotection during open-heart surgery: The importance of anaesthetics. Br J Pharmacol 153: 21-33, 2008.

5. Amirghofran AA, Nick N, Amiri M and Hemmati R: Use of cardiopulmonary bypass for management of massive air embolism during hysteroscopic metroplasty. J Extra Corpor Technol 48: 198-200, 2016.

6. Brouwer ME and McMeniman WJ: Seizures following cardiopulmonary bypass. J Extra Corpor Technol 48: 137-140, 2016.

7. Plicner D, Stoliński J, Wąsowicz M, Gawęda B, Hymczak H, Kapelak B, Drwiła R and Undas A: Preoperative values of inflammatory markers predict clinical outcomes in patients after $\mathrm{CABG}$, regardless of the use of cardiopulmonary bypass. Indian Heart J 68 Suppl 3: S10-S15, 2016.

8. Pinto A, Immohr MB, Jahn A, Jenke A, Boeken U, Lichtenberg A and Akhyari P: The extracellular isoform of superoxide dismutase has a significant impact on cardiovascular ischaemia and reperfusion injury during cardiopulmonary bypass. Eur J Cardiothorac Surg 50: 1035-1044, 2016.

9. Lu T, Jiang B, Wang XL and Lee HC: Coronary arterial BK channel dysfunction exacerbates ischemia/reperfusion-induced myocardial injury in diabetic mice. Appl Physiol Nutr Metab 41: 992-1001, 2016.

10. Aragón JP, Condit ME, Bhushan S, Predmore BL, Patel SS, Grinsfelder DB, Gundewar S, Jha S, Calvert JW, Barouch LA, et al: Beta3-adrenoreceptor stimulation ameliorates myocardial ischemia-reperfusion injury via endothelial nitric oxide synthase and neuronal nitric oxide synthase activation. J Am Coll Cardiol 58: 2683-2691, 2011.

11. Benter IF, Babiker F, Al-Rashdan I, Yousif M and Akhtar S: RU28318, an aldosterone antagonist, in combination with an ACE inhibitor and angiotensin receptor blocker attenuates cardiac dysfunction in diabetes. J Diabetes Res 2013: 427693, 2013.

12. Möhlenkamp S, Weinreich G, Neumann T, Voshaar T and Teschler H: Medical therapy of heart and lung diseases. Effects on the respective other organ. Herz 39: 15-24, 2014 (In German).

13. Li J, Hong Z, Liu H, Zhou J, Cui L, Yuan S, Chu X and Yu P: Hydrogen-rich saline promotes the recovery of renal function after ischemia/reperfusion injury in rats via anti-apoptosis and anti-inflammation. Front Pharmacol 7: 106, 2016.

14. Okamoto A, Kohama K, Aoyama-Ishikawa M, Yamashita H, Fujisaki N, Yamada T, Yumoto T, Nosaka N, Naito H, Tsukahara K, et al: Intraperitoneally administered, hydrogen-rich physiologic solution protects against postoperative ileus and is associated with reduced nitric oxide production. Surgery 160: 623-631, 2016.

15. Gaafar AGA, Messiha BAS and Abdelkafy AML: Nicorandil and theophylline can protect experimental rats against complete Freund's adjuvant-induced rheumatoid arthritis through modulation of JAK/STAT/RANKL signaling pathway. Eur J Pharmacol 822: 177-185, 2018

16. Dodington DW, Desai HR and Woo M: JAK/STAT-emerging players in metabolism. Trends Endocrinol Metab 29: 55-65, 2018.

17. Nunes C, Almeida L, Barbosa RM and Laranjinha J: Luteolin suppresses the JAK/STAT pathway in a cellular model of intestinal inflammation. Food Funct 8: 387-396, 2017.

18. Cai W, Yang X, Han S, Guo H, Zheng Z, Wang H, Guan H, Jia Y, Gao J, Yang T, et al: Notch1 pathway protects against burn-induced myocardial injury by repressing reactive oxygen species production through JAK2/STAT3 signaling. Oxid Med Cell Longev 2016: 5638943, 2016. 
19. Zhang M, Wang X, Wang X, Hou X, Teng P, Jiang Y, Zhang L, Yang X, Tian J, Li G, et al: Oxymatrine protects against myocardial injury via inhibition of JAK2/STAT3 signaling in rat septic shock. Mol Med Rep 7: 1293-1299, 2013.

20. Yang Y, Duan W, Jin Z, Yi W, Yan J, Zhang S, Wang N, Liang Z, Li Y, Chen W, et al: JAK2/STAT3 activation by melatonin attenuates the mitochondrial oxidative damage induced by myocardial ischemia/reperfusion injury. J Pineal Res 55: 275-286, 2013.

21. Li L, Li M, Li Y, Sun W, Wang Y, Bai S, Li H, Wu B, Yang G, Wang R, et al: Exogenous H2S contributes to recovery of ischemic post-conditioning-induced cardioprotection by decrease of ROS level via down-regulation of NF- $\kappa$ B and JAK2-STAT3 pathways in the aging cardiomyocytes. Cell Biosci 6: 26, 2016

22. Qiao S, Mao X, Wang Y, Lei S, Liu Y, Wang T, Wong GT, Cheung $\mathrm{CW}, \mathrm{Xia} \mathrm{Z}$ and Irwin MG: Remifentanil preconditioning reduces postischemic myocardial infarction and improves left ventricular performance via activation of the janus activated kinase-2/signal transducers and activators of transcription-3 signal pathway and subsequent inhibition of glycogen synthase kinase-3 $\beta$ in rats. Crit Care Med 44: e131-e145, 2016.

23. Terrell AM, Crisostomo PR, Wairiuko GM, Wang M, Morrell ED and Meldrum DR: Jak/STAT/SOCS signaling circuits and associated cytokine-mediated inflammation and hypertrophy in the heart. Shock 26: 226-234, 2006.

24. Zhang J, Wu Q, Song S, Wan Y, Zhang R, Tai M and Liu C: Effect of hydrogen-rich water on acute peritonitis of rat models. Int Immunopharmacol 21: 94-101, 2014

25. Chen K, Wang N, Diao Y, Dong W, Sun Y, Liu L and Wu X: Hydrogen-rich saline attenuates brain injury induced by cardiopulmonary bypass and inhibits microvascular endothelial cell apoptosis via the PI3K/Akt/GSK3 $\beta$ signaling pathway in rats. Cell Physiol Biochem 43: 1634-1647, 2017.

26. Berg K, Haaverstad R, Astudillo R, Björngaard M, Skarra S, Wiseth R, Basu S and Jynge P: Oxidative stress during coronary artery bypass operations: Importance of surgical trauma and drug treatment. Scand Cardiovasc J 40: 291-297, 2006.

27. Jain U: Myocardial injury during reoperation for coronary artery bypass surgery. J Cardiothorac Vasc Anesth 9: 389-394, 1995.

28. Gao Y, Yang H, Fan Y, Li L, Fang J and Yang W: Hydrogen-rich saline attenuates cardiac and hepatic injury in doxorubicin rat model by inhibiting inflammation and apoptosis. Mediators Inflamm 2016: 1320365, 2016.

29. Meng X, Chen H, Wang G, Yu Y and Xie K: Hydrogen-rich saline attenuates chemotherapy-induced ovarian injury via regulation of oxidative stress. Exp Ther Med 10: 2277-2282, 2015.

30. Tian R, Hou Z, Hao S, Wu W, Mao X, Tao X, Lu T and Liu B Hydrogen-rich water attenuates brain damage and inflammation after traumatic brain injury in rats. Brain Res 1637: 1-13, 2016.

31. Elahi MM, Khan JS and Matata BM: Deleterious effects of cardiopulmonary bypass in coronary artery surgery and scientific interpretation of off-pump's logic. Acute Card Care 8: 196-209, 2006.

32. Crawford JH, Hull MS, Borasino S, Steenwyk BL, Hock KM, Wall $\mathrm{K}$ and Alten JA: Adrenal insufficiency in neonates after cardiac surgery with cardiopulmonary bypass. Paediatr Anaesth 27: 77-84, 2017.

33. Pinto A, Jahn A, Immohr MB, Jenke A, Döhrn L, Kornfeld M, Lichtenberg A, Akhyari P and Boeken U: Modulation of immunologic response by preventive everolimus application in a rat CPB model. Inflammation 39: 1771-1782, 2016.

34. De Somer F: End-organ protection in cardiac surgery. Minerva Anestesiol 79: 285-293, 2013

35. Menasché P: Strategies to improve myocardial protection during extracorporeal circulation. Shock 16 (Suppl 1): 20-23, 2001

36. Ohsawa I, Ishikawa M, Takahashi K, Watanabe M, Nishimaki K, Yamagata K, Katsura K, Katayama Y, Asoh S and Ohta S: Hydrogen acts as a therapeutic antioxidant by selectively reducing cytotoxic oxygen radicals. Nat Med 13: 688-694, 2007.

37. Zhao S, Yang Y, Liu W, Xuan Z, Wu S, Yu S, Mei K, Huang Y, Zhang P, Cai J, et al: Protective effect of hydrogen-rich saline against radiation-induced immune dysfunction. J Cell Mol Med 18: 938-946, 2014.

38. Aoki K, Nakao A, Adachi T, Matsui Y and Miyakawa S: Pilot study: Effects of drinking hydrogen-rich water on muscle fatigue caused by acute exercise in elite athletes. Med Gas Res 2: 12, 2012

39. Zhang J,HaoH, Chen M, Wang H,Feng Z and Chen H: Hydrogen-rich water alleviates the toxicities of different stresses to mycelial growth in Hypsizygus marmoreus. AMB Express 7: 107, 2017.
40. Yang Y, Li B, Liu C, Chuai Y, Lei J, Gao F, Cui J, Sun D, Cheng Y, Zhou C and Cai J: Hydrogen-rich saline protects immunocytes from radiation-induced apoptosis. Med Sci Monit 18: BR144-BR148, 2012.

41. Cui W, Gao C, Fang P, Lin G and Shen W: Alleviation of cadmium toxicity in Medicago sativa by hydrogen-rich water. J Hazard Mater 260: 715-724, 2013.

42. Wang X, Yu P, YongYang, Liu X, Jiang J, Liu D and Xue G: Hydrogen-rich saline resuscitation alleviates inflammation induced by severe burn with delayed resuscitation. Burns 41: 379-385, 2015

43. Liu YQ, Liu YF, Ma XM, Xiao YD, Wang YB, Zhang MZ, Cheng AX, Wang TT, Li JL, Zhao PX, et al: Hydrogen-rich saline attenuates skin ischemia/reperfusion induced apoptosis via regulating Bax/Bcl-2 ratio and ASK-1/JNK pathway. J Plast Reconstr Aesthet Surg 68: e147-e156, 2015.

44. Shingu C, Koga H, Hagiwara S, Matsumoto S, Goto K, Yokoi I and Noguchi T: Hydrogen-rich saline solution attenuates renal ischemia-reperfusion injury. J Anesth 24: 569-574, 2010.

45. Fang Y, Fu XJ, Gu C, Xu P, Wang Y, Yu WR, Sun Q, Sun XJ and Yao M: Hydrogen-rich saline protects against acute lung injury induced by extensive burn in rat model. J Burn Care Res 32: e82-e91, 2011.

46. Guo S, Gao C, Xiao W, Zhang J, Qu Y, Li J and Ye F: Matrine protects cardiomyocytes from ischemia/reperfusion injury by regulating HSP70 expression via activation of the JAK2/STAT3 pathway. Shock: Feb 1, 2018 (Epub ahead of print).

47. Eid RA, Alkhateeb MA, Eleawa S, Al-Hashem FH, Al-Shraim M, El-Kott AF,Zaki MSA, Dallak MA and Aldera H: Cardioprotective effect of ghrelin against myocardial infarction-induced left ventricular injury via inhibition of SOCS3 and activation of JAK2/STAT3 signaling. Basic Res Cardiol 113: 13, 2018.

48. Hilfiker-KleinerD, Hilfiker A, Fuchs M, Kaminski K, Schaefer A, Schieffer B, Hillmer A, Schmiedl A, Ding Z, Podewski E, et al: Signal transducer and activator of transcription 3 is required for myocardial capillary growth, control of interstitial matrix deposition, and heart protection from ischemic injury. Circ Res 95: 187-195, 2004

49. Wang Y, Wong GT, Man K and Irwin MG: Pretreatment with intrathecal or intravenous morphine attenuates hepatic ischaemia-reperfusion injury in normal and cirrhotic rat liver. Br J Anaesth 109: 529-539, 2012.

50. Li Y, Zhu W, Tao J, Xin P, Liu M, Li J and Wei M: Fasudil protects the heart against ischemia-reperfusion injury by attenuating endoplasmic reticulum stress and modulating SERCA activity: The differential role for PI3K/Akt and JAK2/STAT3 signaling pathways. PLoS One 7: e48115, 2012.

51. Luan HF, Zhao ZB, Zhao QH, Zhu P, Xiu MY and Ji Y: Hydrogen sulfide postconditioning protects isolated rat hearts against ischemia and reperfusion injury mediated by the JAK2/STAT3 survival pathway. Braz J Med Biol Res 45: 898-905, 2012.

52. Huang CH, Tsai MS, Chiang CY, Su YJ, Wang TD, Chang WT, Chen HW and Chen WJ: Activation of mitochondrial STAT-3 and reduced mitochondria damage during hypothermia treatment for post-cardiac arrest myocardial dysfunction. Basic Res Cardiol 110: 59, 2015.

53. Wu L, Tan JL, Wang ZH, Chen YX, Gao L, Liu JL, Shi YH, Endoh M and Yang HT: ROS generated during early reperfusion contribute to intermittent hypobaric hypoxia-afforded cardioprotection against postischemia-induced $\mathrm{Ca}(2+)$ overload and contractile dysfunction via the JAK2/STAT3 pathway. J Mol Cell Cardiol 81: 150-161, 2015.

54. Chen G, Tang N, Wang C, Xiao L, Yu M, Zhao L, Cai H, Han L, Xie $\mathrm{C}$ and Zhang Y: TNF- $\alpha$-inducing protein of Helicobacter pylori induces epithelial-mesenchymal transition (EMT) in gastric cancer cells through activation of IL-6/STAT3 signaling pathway. Biochem Biophys Res Commun 484: 311-317, 2017.

55. Su C, Zhang P, Liu J and Cao Y: Erianin inhibits indoleamine 2,3-dioxygenase-induced tumor angiogenesis. Biomed Pharmacother 88: 521-528, 2017.

56. Tao B, Liu L, Wang N, Tong D, Wang W and Zhang J: Hydrogen-rich saline attenuates lipopolysaccharide-induced heart dysfunction by restoring fatty acid oxidation in rats by mitigating c-jun n-terminal kinase activation. Shock 44: 593-600, 2015.

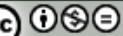

This work is licensed under a Creative Commons Attribution-NonCommercial-NoDerivatives 4.0 International (CC BY-NC-ND 4.0) License. 